\title{
Burt- Or Coleman-Type Rents, Or a Bit of Both? Knowledge Management Strategies in Suppliers' Networks
}

\author{
Gilda Antonelli ${ }^{1}$, Edoardo Mollona ${ }^{2} \&$ Luigi Moschera ${ }^{3}$ \\ ${ }^{1}$ Department of Law, Economics, Management and Quantitative Methods, University of Sannio, Italy \\ ${ }^{2}$ Department of Computer Science and Engineering, University of Bologna, Italy \\ ${ }^{3}$ Department of Management and Economics, University of Naples Parthenope, Italy \\ Correspondence: Gilda Antonelli, Department of Law, Economics, Management and Quantitative Methods, \\ University of Sannio, Benevento, Italy. E-mail: gilda.antonelli@gmail.com
}

Received: October 20, 2018

Accepted: November 17, 2018

Online Published: November 26, 2018

doi:10.5539/ijbm.v13n12p274

URL: https://doi.org/10.5539/ijbm.v13n12p274

\begin{abstract}
Nodal Enterprises (NEs) (Dyer \& Nobeoka, 2000) create value by exploiting their position at the center of networks of supplier firms. In managing these networks of organizations, however, NEs face a dilemma: how much knowledge must be shared with partners in the value-chain? In this paper, we propose that knowledge sharing must be managed dynamically.

Building on selected applications of social network theory to clusters' analysis (Kogut, 2000), we assume that NEs manage a combination of two types of rents when they share knowledge among their networked firms: "Coleman-type" and "Burt-type" rents. How the combination between the two dynamically unfolds is an unexplored issue. Using a computer simulation model, we explore robustness of alternative strategies of knowledge sharing among networked firms. Learning from our simulation experiments, we suggest a desired inter-temporal pattern of knowledge sharing and we show how the steady-state of knowledge-sharing depends counterintuitively on the speed at which knowledge leaks among the firms that are connected in the network.
\end{abstract}

Keywords: knowledge sharing, knowledge management strategies, computer simulation model, dynamic rents

\section{Introduction}

Nodal Enterprises (NEs) (Dyer \& Nobeoka, 2000) create value by exploiting their position at the center of networked of suppliers firms. In managing the network of suppliers, however, NEs face a thorny choice. On the one hand, by sharing their know-how with suppliers, they may increase the value of the supply chain. Sharing, however, implies the risk of losing the grip on distinctive knowledge. Therefore, on the other hand, NEs aim at minimizing knowledge transfer. However, the less knowledge is shared with suppliers, the weaker is the value chain in terms of innovation capacity. This is because higher levels of process complexity and customization require greater cooperation between partners (Heide, 1994). Work in practitioner-oriented and the academic literature (Uzzi, 1997; Magretta, 1998; Sahin \& Robinson, 2005; Watson \& Zheng, 2005; Kulp et al., 2004; Frohlich, 2002; Frohlich \& Westbrook, 2001; Eden, Hitt, \& Ireland, 2008; Cua et al., 2001; Tortoriello et al., 2015) emphasize the role of network integration and coordination as an important determinant of value creation and innovation.

How NEs can manage this coordination problem over time?

In received literature, we suggest, the analysis of alternative longitudinal strategies of knowledge sharing, at best, partial.

The contribution of this study is to suggest that, rather than the choice between sharing or not sharing knowledge within a supply network, NEs should care about how symmetrically the knowledge is distributed in the network and whether they are able to guarantee a continuous process of knowledge creation. In this paper, we propose that it is not the knowledge per se that produces sustainable advantage but the process of continuously creating and sharing knowledge.

Previous literature teased out the governance mechanisms that discourage free riding, such as trust (Sako, 1992), co-specialization (Dyer and Singh, 1996), and quasi-hierarchy (Dyer \& Nobeoka, 2000). 
Yet, these studies are static representations of an existing network structure, or retrospective field studies that propose conjectures on the trajectory that a specific supplier network undertook to reach the observed status. In our study, we address the knowledge-sharing problem in a dynamic perspective. In particular, building on social network theory (Coleman, 1990; Burt, 1987, 1992, 2000; Kogut, 2000) we address the inter-temporal sustainability of knowledge sharing strategies within networks.

The heterogeneity of NE networks, however, poses significant barriers to systematic investigations of inter-temporal dynamics (Staber, 1998).

Yet, drawing on a computer simulation model, we are able to investigate an ideal-type of a NE with its connected network of suppliers. We build a formal model that captures the typical traits of a NE that interacts with a supply chain. This approach has been previously used in organizational and strategy research (Malerba et al., 1999; Gary, 2005; Mollona, 2017). By the means of computer simulation, we explore the behavior of the formal model. To contribute to future empirical research, we use a set of simulation experiments to generate a set of testable propositions. Specifically, the simulation experiments suggest how the competitive value of knowledge obsolesces over time is crucial in explaining rents' preservation for NEs.

To build our model and to tackle our research question - How and when is desirable for NEs to share their knowledge with suppliers? - we mobilize three streams of literature: the analysis of rents in networks, the literature on knowledge sharing in inter-organizational networks and the studies on bargaining power in networks.

The paper is organized as follows. In the following section we present our theoretical framework, then we describes our computational research strategy. Section three presents the formal model. We present the experimental protocol in Section four and we report results from a set of simulation experiments and discuss the implications presenting a set of empirically testable propositions in Section five. The final section is dedicated to conclusions.

\section{Theoretical Framework}

\subsection{The Type of Rents Emerging in Networks of Firms}

Helper (1990) found that close supplier-manufacturer relationships in the auto industry are distinctive for their "thick" information exchange of tacit and proprietary know-how. Romo and Schwartz's (1995) and Dore's (1983) suggest that actors embedded in local production networks create their competitive advantage by cultivating long-term, cooperative ties. The basic conjecture of this literature is that embeddedness creates economic opportunities that are difficult to replicate via markets, contracts, or vertical integration (Uzzi, 1995).

As suggested by Kogut (2000), in a network of firms, two kinds of rents may emerge. The first type of rent is defined by borrowing the concepts of 'structural hole' and 'non-redundant tie' put forward by Burt (1992). A structural hole is a lack of connection between two nodes and a 'non-redundant tie' is a tie that represents the only path between two nodes. When a node occupies a structural node, it acquires a powerful brokerage position since it becomes the only route to connect the previously isolated nodes. Thus, the so-called Burt rent derives from a privileged position in a network and accrues to the firm that plays the role of broker by bridging structural holes and arbitrating the information flows between agents with loose ties with each other. Tortoriello et al. (2015), for example, investigated actors' individual positions in innovation network.

The definition of the second type of rent follows from Coleman's analysis of the role of multiple redundant ties among nodes in a network (1990). According to Coleman, redundant ties produce a dense web of relationships in which nodes have reciprocal control. This reciprocal control results in the solution of collective action problems and in improved coordination among firms.

While in the case of Burt-type rents, the unit of accumulation of rents is a single firm, which owns a valuable resource to which clear property rights are associated, in the case of Coleman rents the unit of accumulation is a group of firms that jointly retain a valuable resources without clear property rights associated. Burt and Coleman-type rents are often empirically intertwined but because of their theoretically different nature, it is difficult to analyze them separately.

\subsection{Type of Rents and NE'S Knowledge Management Strategy in Inter-Organizational Network}

Knowledge transfer improves innovative capabilities (Huizingh, 2011), increases the pace of innovation and strengthens competitive advantage (Foss et al., 2010). In this context, NEs need to manage their external networks whether they are in the structure of informal or formal alliances (Dyer \& Nobeoka, 2000). Therefore, knowledge integration is an important determinant of rents. 
NEs can generally choose between two different knowledge management strategies.

First, with the aim of generating absorptive capacity (Cohen \& Levinthal, 1990), they can share and collect knowledge among their inter-organizations suppliers' networks. They enact this strategy by facilitating connections among all the organizations in different ways: supporting the creation of consortia, implementing information and communication technologies platforms or choosing suppliers that are collocated mainly in the same geographic cluster. In fact, suppliers that are collocated in the same area share redundant connections and tacit trust, social and economic relations and other advantages (Narula \& Santangelo, 2012). In his paper on the embeddedness paradox, Uzzi (1995) demonstrated that the more competitive advantage depends on reaching positive-sum solutions to inter-firm coordination problems, the more organization networks, rather than other forms of organization, will dominate competitive processes. He argues that the unique expectations of reciprocity and cooperative resource sharing of embedded ties generate investments that cannot be achieved through arm's-length ties that are based on immediate gain. This knowledge sharing seems to be connected to Coleman-type rents, which accrue from the density of collaborative relationships in networks.

Despite the gains that accrue to NEs that are able to share knowledge with other networked firms, the public good nature of shared knowledge entails ambiguity of ownership rights, incentives for free riding and problems of agency. The more knowledge a company has in a particular field, the easier is to manage inter-firms relationships and to profit from the knowledge that comes from others.

Therefore, knowledge management strategy that NEs is guided as well by the fear of the "dark side of knowledge sharing" (Frishammar, Ericsson, \& Patel, 2015). By sharing important knowledge with other actors a $\mathrm{NE}$, in turn, lowers firm performance (Easterby-Smith et al., 2008). To avoid the waste of competitive advantage that comes from innovation, the NEs can manage the network by taking the organizations a part one from the other, and by acting as a broker in the knowledge sharing process. They can develop and manage only dyadic connections with suppliers that are geographically far one from another. This notion of distance, however, does not need to be necessarily referred to geography. NEs may bridge firms that are located in fields that are culturally and institutionally different. As Greenwood and Suddaby suggest, firms mat exploit the benefit of 'a network positions that bridges fields' by 'increasing their awareness of alternatives' (2006: 38). This strategy, which is based on the exploitation of brokerage, is likely to rest upon the appropriation of Burt-type rents.

Therefore, according to the literature, both type of rents seem to have specific strengths and weaknesses. What is left under researched is the relative stability over time of the pillars on which the rents ground.

\subsection{Bargaining Power and Different Types of Rents}

To generate Burt-type rents NEs occupy structural holes between other organizations. The adopted brokerage strategy assigns bargaining power to NEs. Bargaining power refers to the ability to win concessions from the other parties involved in a negotiation and to affect favorably the outcome (Dwyer \& Walker, 1981) (Note 1). Based on the received literature, in inter-organizational networks NEs have typically greater context-based sources of bargaining power (Yan \& Gray, 2001; Coff, 1999) because they often are larger firms eventually able to build international collaborative networks or have private online marketplaces and proprietary solutions from their partners. NEs often have larger resource-based sources of bargaining power (Yan \& Gray, 2001; Coff, 1999) because they are frequently large firms that bring more resources, technical know-how and expertise to support the industry exchange, especially during innovation processes.

In the case of inter-organizational networks in which firms enjoy coordination rents that are produced by shared knowledge, we are typically in presence of Coleman-type rents since intellectual property right resides at the network, rather than firm level' (Dyer \& Nobeoka, 2000). Thus, for NEs, knowledge sharing strategy that implies the switching from Burt-type to Coleman-type rents and the simultaneous subsequent erosion of portions of bargaining power. In this framework, received literature reports a variety of mechanisms that supports NEs in counterbalancing the emerging free riding problems. These mechanisms range from mutual trust between customer and supplier, which develops through shared knowledge and the dense exchange of information and technology (Sako, 1992), to reciprocal monitoring (Kogut, 2000: 421).

In addition, a powerful force that preserves an inter-organizational network from disintegrating after the pressures of individual opportunism is the perspective of sharing portions of Coleman-type rents (Rota et al., 2002). In the Toyota supply-chain, for example, Kogut (2000) and Dyer and Nobeoka (2000) report the rules leading to the sharing of obtained productivity gains between makers and assembler, and Kogut (2000: 422) acutely explains how coordination rents, once distributed, provide a sort of efficiency wage that induce cooperation. In this respect, Coleman-type rents become quasi-rents that accrue to participants of suppliers networks as the consequence of co-specialization (Dyer \& Singh, 1996), which are the difference between the 
gains that accrue from participating to knowledge sharing in the network and the gains from the best alternative use of own resources outside it (Milgrom \& Roberts, 1992).

In addition, in switching towards Coleman-rents, not necessarily NEs entirely give away bargaining power, rather it seems that portions of bargaining power remain with NEs and Burt-type rents persist intertwined with Coleman-type rents. For example, NEs may maintain privileged access to global markets. Empirical studies suggest that, in those inter-organizational networks that are successful in sharing knowledge, joining firms typically enjoy augmented chances to initiate commercial relationships with clients outside the suppliers' network and this is not perceived necessarily as breaching a code or reciprocity or to free ride. As reported by Ahmadjian and Lincol (2001: 690), Toyota, for example, saw as an advantage the fact that one of its supplier, Denso, had developed strong relationships with other customers since this additional knowledge contributes to depict a 'better picture' of the automobile industry possibly leading to innovation proposal.

What emerges from received literature and empirical research is that how NEs maintain an inter-organizational network together, after knowledge sharing processes have been initiated, is a blend of trust, reciprocity and the perspective of sharing Coleman-rents, on the one hand, and the preservation of authority, bargaining power and portions of Burt-type rents, on the other.

What remained relatively unexplored is how the integration of Coleman- and Burt-type rents is dynamically managed over time. The transition from Burt-type to Coleman-type rents is far from a linear and predictable one and it requires an accurate analysis of the trajectory that the suppliers' network walks over. Importantly, a dynamic analysis of rents requires considering how the characteristics of shared knowledge change over time. General dynamic hypotheses are needed that explain how dynamics of rents and bargaining power within inter-organizational networks are connected to the dynamics of knowledge deployment, and which are the consequences in the medium run, of a NE strategic behavior. However, previous research generally accepts that the value of knowledge remains stable over time. Knowledge is not stable in time and rents depends on the obsolescence of the value of knowledge. How knowledge obsolescence and rents dynamically interact over time is an open question.

\section{Methodology}

The longitudinal and complex nature of the described interaction between a NE and its networked firms makes deriving its implications fairly ambiguous. It is difficult to explicate how the processes unfold over time in different contexts to yield different aggregate results. The unfolding of these processes can be observed, however, in a computer simulation. Thus, to articulate theoretical conjectures concerning the unfolding dynamics of knowledge sharing in supplier' networks, we adopt a research strategy grounded on mathematical modelling and computer simulation. Mathematical modeling entails the formalization of a plausible description of typical pressures, forces and decision-making at work within a stylized knowledge sharing process. Once the formalism is generated, we use computer simulation to derive emerging behavior by a process of deduction. Thus, computer simulations provide an experimental environment where researchers are able to scrutinize closely the link between a structure of causal relations, crystallized in a set of assumptions, and the behavior that those assumptions postulate (Lant \& Mezias, 1992; Sastry., 1997; Gary, 2005).

\section{The Model}

The model includes several equations that govern the behavior of a number of state variables. State variables capture the key concepts that emerge in the presented theoretical framework (see table 1). Standard continuous-time notation represents differential equations to describe the behavior (Note 2)of state variables. 
Table 1.

\begin{tabular}{|c|c|c|}
\hline Concept & Description & Unit of Measure \\
\hline NE Welfare (S) & Sales of the focal NE. & Currency. \\
\hline Population of Network (P) & $\begin{array}{l}\text { Size of the population of firms in the suppliers' network. The } \\
\text { health of this population is connected to NE's market share or } \\
\text { to the possibility to direct sales towards clients outside the } \\
\text { original suppliers' network. Thus, it is regarded as an indicator } \\
\text { of the welfare of the suppliers' network since it captures the } \\
\text { carrying capacity in terms of the number of suppliers with } \\
\text { fixed average breakeven sales. }\end{array}$ & $\mathrm{N}^{\circ}$ of firms. \\
\hline Bargaining power of Suppliers (B) & $\begin{array}{l}\text { Degree of diversification of suppliers' sales towards clients } \\
\text { outside the original network. }\end{array}$ & $\begin{array}{l}\text { Percentage of global market } \\
\text { accessible by suppliers. }\end{array}$ \\
\hline Level of shared knowledge (K) & $\begin{array}{l}\text { Level of knowledge shared between NE and suppliers and that } \\
\text { result in the advancement of production processes at work in } \\
\text { the network. The advancement is obtained through } \\
\text { collaboration between NE and suppliers and requires } \\
\text { knowledge-transfer from NE towards suppliers. }\end{array}$ & $\begin{array}{l}\text { Percentage of technological } \\
\text { upgrade achieved compared to an } \\
\text { attainable } \\
\text { benchmark. }\end{array}$ \\
\hline
\end{tabular}

To capture pressures on NE's welfare, we modeled average sales. An increase in sales over past average may be the result of a larger number of units sold at the same contribution margin or it may follow from the request of a premium price over an unchanged number of units sold of a differentiated product.

The rate of change of sales of local main contractor is calculated by multiplying actual sales by a factor $\pi$ that captures competitive advantage that underpins rent generation. We compare the obtained value to the smoothed average of past sales to create a pressure upward or downward. The adjustment of sales above or below the average occurs with a certain level of inertia that is captured by the factor $\tau^{s}$. Therefore, our modelling portrays change in sales as an inertial process that follows from the adaptation to the change in the value of $\pi$.

$$
S_{t+\Delta t}=S_{t}+\int_{t}^{t+\Delta t} \dot{S} \quad \text { and } \quad \dot{S}=\frac{S_{t} \cdot \pi-S_{t}}{\tau^{s}}
$$

NE's rent generation mechanism $\pi$ has been modeled as the product of two rent generation mechanisms. The first element captures Burt-type rents that originate from bargaining power and brokerage over a large number of suppliers $\left(\pi^{B}\right)$. The second component describes Coleman-type rents that accrue from knowledge sharing in the co-localized network $\left(\pi^{C}\right)$. For values of $\pi$ greater than one, a rent exists and sales are pushed upward in respect to past average; for values of $\pi$ smaller than one, sales are pushed below their historical average. In our formulation, NE's rent generation is a weighted average of Burt and Coleman type rents $\left(\pi^{B}\right.$ and $\left.\pi^{C}\right)$. The use of a weighted average reflects the idea that these different types of rents are usually intertwined in their affecting a NE's competitive advantage. The weight in the average is $\phi$ :

$$
\pi=\pi^{B} \cdot \phi+\pi^{C} \cdot(1-\phi)
$$

In the model, Coleman-type rents follows from the level of knowledge shared within the NE. We considered a standardized measure: the difference $1-k^{g}$ where $k^{g}$ is the gap between actual knowledge shared and a reference level, which is the level of knowledge sharing theoretically achievable.

$$
\pi^{C}=1+\left(1-k^{g}\right)
$$

On the other hand, Burt-type rents are influenced by two elements. First, in general, the larger the population of suppliers, the higher the bargaining power of the NE since this latter is able to bargain among numerous suppliers. Second, as the level of knowledge shared in the network increases, suppliers' bargaining power increases since they become theoretically able to diversify their sales towards external clients; then, local NE needs to bargain with suppliers to acquire innovation. Here, we are assuming the knowledge sharing upgrades suppliers' capabilities with portions of generic know-how.

Thus, in equation 4, Burt-type rents increases with the ratio between total sales of supplier' network directed to $\mathrm{NE}$ and the value of NE's procurement $\left(v_{c}^{p}\right)$. Total sales directed to NE are obtained by multiplying the population of suppliers firms $(P)$ by the average breakeven sales $(b)$; the value obtained is then decreased by the proportion of suppliers that are empowered and may exercise free riding by using acquired knowledge outside the original cluster. We name the potential for opportunism $\left(O_{t}\right)$ 


$$
\pi^{B}=\left(\frac{P \cdot \tilde{b} \cdot\left(1-O_{t}\right)}{v_{c}^{p}}\right) .
$$

The adjustment of the proportion of free-riding suppliers is a weighted average of recent information about proportion of free riders theoretically achievable given the actual level of knowledge shared in the network $\left(O^{t}\right)$ and the actual proportion of empowered suppliers $\left(O_{t}\right)$.

The weighting factor is $\tau^{O}$, which sets the pace at which suppliers recognize their chances for free-riding (Note 3 ). The idea here is that knowledge diffusion empowers a population of suppliers and creates pressures that accumulates and gradually push local suppliers to diversify their sales.

We want to represent a decision-making process that takes place at the level of a population of firms. Thus, a smoothing process seems particularly appropriate to represent the gradual converging of different actors within a population towards an aggregate free-riding behavior as the consequence of the incentives that emerge, and display their effects, incrementally in time.

Thus, opportunism follows from knowledge sharing over time with a certain level of inertia, this latter captured by the weighting factor is $\tau^{O}$ :

$$
O_{t+\Delta t}=O_{t}+\int_{t}^{t+\Delta t} \dot{O} \quad \text { and } \quad \dot{O}=\frac{o_{t}^{t}-O_{t}}{\tau^{o}}
$$

The proportion of free-riders suppliers theoretically achievable is a function of the gap between theoretically achievable and actual knowledge shared $\left(k^{g}\right)$. When the gap is zero $\left(k^{g}=0\right)$, knowledge has been entirely shared between suppliers and NE. Then, suppliers may potentially use the transferred knowledge to diversify their clients. When NE does no share any knowledge, $k^{g}=1$ and there is no chance for suppliers to diversify their clients. Therefore,

$$
0^{t}=1-k^{g}
$$

The NE, as local suppliers show opportunistic behavior, may interrupt knowledge sharing since it may recognize that coordination rents do not balance out the loss of bargaining power. Thus, in the following equation, desired level of knowledge sharing $k^{d}$ is a decreasing function of the level of diversification of sales of suppliers:

$$
k^{d}=1-O_{t} .
$$

The process of knowledge sharing is modelled as depending on two elements. First element is the gap between actual level of shared knowledge and the theoretically achievable level of shared knowledge. The second element is the level of shared knowledge as desired by the focal firm. This latter may accelerate or slow down the knowledge sharing process. The process of changing the level of knowledge sharing is not instantaneous; the inertia is captured by the factor $\tau^{K}$.

$$
K_{t+\Delta t}=K_{t}+\int_{t}^{t+\Delta t} \dot{K} \quad \text { and } \quad \dot{K}=\frac{k_{t}^{g} \cdot k_{t}^{d}}{\tau^{K}}
$$

The knowledge gap is calculated in the following equation by dividing the difference between theoretically achievable level $k$ and the actual level of shared knowledge by the theoretically achievable level. This standardized scaling was chosen for convenience; since we did not have data to empirically calibrate a plausible absolute value for knowledge gap and level of shared knowledge, we developed a formulation that standardizes the value of $k^{g}$ and yields operating points in the zero-unit interval (Sastry, 1997).

$$
k^{g}=\frac{\left(\tilde{k}-K_{t}\right)}{\widetilde{k}}
$$

To mimic the pace at which population of firms within the local suppliers' network grows, we used again a smoothing average process. In this way, we represent the structural inertia that separates the emerging of an opportunity for new firms to start up, or the worsening of conditions for extant firms, and the actual modification of the size of firms' population. The number of firms that the suppliers' network may support depends on total potential market.

Total carrying capacity of the network is the sum of the value of procurement of local NE 
$\left(v_{c}^{p}\right)$ and the sales obtained from diversification towards other clients external to the local network. Diversified sales are calculated by multiplying the estimated size of global market $(\varepsilon)$ by the proportion of empowered suppliers that can diversify towards markets outside the geographical cluster $\left(O_{t}\right)$. Total available market is then divided by the average volume of breakeven sales $(\tilde{b})$ to obtain the number of firms that may survive in the local network (Note 4). The population of firms within the cluster is then updated by comparing potential population with actual population. The comparison, however, leads to adjustment only with delay. The delay is captured by the factor $\tau^{P}$.

$$
P_{t+\Delta t}=P_{t}+\int_{t}^{t+\Delta t} \dot{P} \quad \text { and } \quad \dot{P}=\frac{\frac{v_{c}^{p}+\varepsilon \cdot o_{t}}{\tilde{b}}-P_{t}}{\tau^{P}}
$$

Average breakeven is a parameter and the value of main local contractor procurement is a fixed percentage of value of sales.

$$
v_{c}^{p}=S_{t} \cdot \gamma
$$

Table 2.

\begin{tabular}{lll}
\hline \multicolumn{1}{c}{ Meaning of the parameter } & \multicolumn{1}{c}{ Value } \\
\hline$b$ & Average breakeven sales of suppliers & $500,000,000 \$$ \\
$\gamma$ & Network sales on total NE procurement & $30 \%$ \\
$\mathcal{E}$ & Value of sales from clients external to MNE's network & $10,000,000,000 \$$ \\
$\delta$ & Rate of shared knowledge obsolescence & $10 \%$ of knowledge/year \\
$k$ & Achievable level of shared knowledge & $100 \%$ \\
$\phi$ & Weight of rent type. & 0.5 (percentage) \\
$\tau^{B}$ & Time delay to update suppliers' bargaining power & 4 (months) \\
$\tau^{P}$ & Time delay to update suppliers' network population & 4 (months) \\
$\tau^{S}$ & Time delay to update average sales of MNE & 4 (months) \\
$\tau^{K}$ & Time delay to update level of knowledge shared & 4 (months) \\
$S_{t_{n}}$ & Initial size of average sales of MNE & $500,000,000 €$ \\
$P_{t_{n}}$ & Initial size of suppliers' network population & 30 (firms) \\
$K_{t_{n}}$ & Initial level of knowledge shared with suppliers network & 0 (percentage on achievable) \\
$B_{t_{n}}$ & Initial level of suppliers' bargaining power & 0 (percentage on achievable) \\
\hline
\end{tabular}

\section{The Simulation Experiments}

To start with, we calibrated the computer model by assigning plausible values to its parameters (see table 2). We selected a time horizon of ten years for our simulations and we used a time step of 1 month. Subsequently, we developed a two-step experimental strategy First, we produced a reference simulation pattern with our standard model. In this first setting, we represent the dynamics of knowledge sharing between the NE and a number of suppliers distributed in a network. Second, we introduced an additional assumption: we simulated that the value of the knowledge shared within the cluster erodes over time as this knowledge symmetrically leaks among the suppliers that are connected in the network. Put differently, we assume that knowledge sharing does not assign to co-located suppliers any differentiate capabilities when they try differentiating outside the cluster. We want to simulate how incentives of NE to share knowledge changes as we consider the symmetry in the horizontal distribution of knowledge. Whereas previous studies have considered either vertical knowledge sharing, between a NE and its suppliers, or the horizontal leakage of knowledge among suppliers, we want to consider these two phenomena in combination. We investigated the consequences that the introduction of this assumption brings about.

Our analysis is articulated in two steps. First, we show the reference mode that is the model behavior that we consider the benchmark for our analysis (experiment 1). Then, we report the dynamic implications of introducing the process of leakage and value erosion of shared knowledge (experiment 2). Finally, we discuss a sensitivity 
analysis and investigate the consequences.

\subsection{Reference Mode: Experiment 1}

The experiment 1 produces a typical pattern in which, in a traditional network, knowledge leaks from a NE to suppliers. This leakage triggers a not reversible process leading to an increase of potential for suppliers opportunism.

The simulation experiment elicits a typical pattern of transition. The NE enjoys improved production factors and suppliers achieve enough knowledge to establish commercial relationships with partners outside the original network. In this exchange, taking the perspective of the NE, Burt-type rents expire and Coleman-type rents emerge. In figure 1, on the vertical axis we report the percent increase in rent, which we labeled $\pi$.

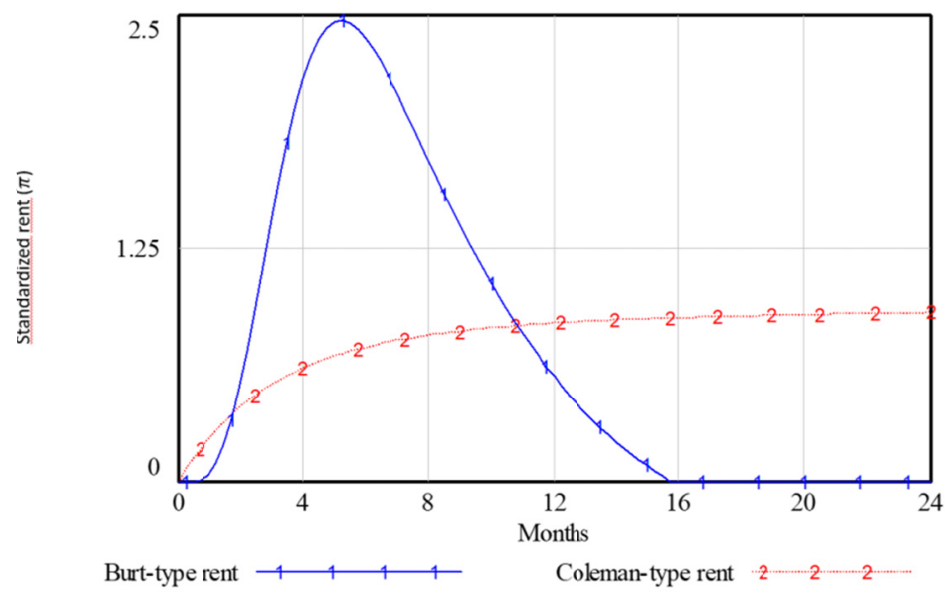

Figure 1.

For example, a value of two reported on the vertical axis signals that rent enjoyed by the NE has increased $200 \%$. In addition, the figure reports the dissection of rents into its two components: Coleman-type rents and Burt-type rents. The figure captures a cycle in which, at the outset, Burt-type rent (curve 1) constitutes the larger contribution to total rent and, in a second stage, Coleman-type rent (curve 2) makes the larger portion of rent. The graph vividly portrays the evolution of a suppliers' network. Knowledge leakage from the NE to suppliers increase the overall quality of the final product. The portion of the rent that stems from knowledge sharing is reported by the growing curve 2. The increasing success of the network increases turnover and attracts further suppliers that connect to the global network. The increase in the number of potential global suppliers produce an increase in the bargaining power of the NE. This is the reason why the Burt-type portion of rent grows more rapidly than the Coleman-type portion of rent. After 7-8 simulated months, however, we assume that the sharing of knowledge redistributes bargaining power in favor of suppliers. This eliminates the Burt-type rent. At this point, NE's rent is produced only by the ability to share knowledge with suppliers. 


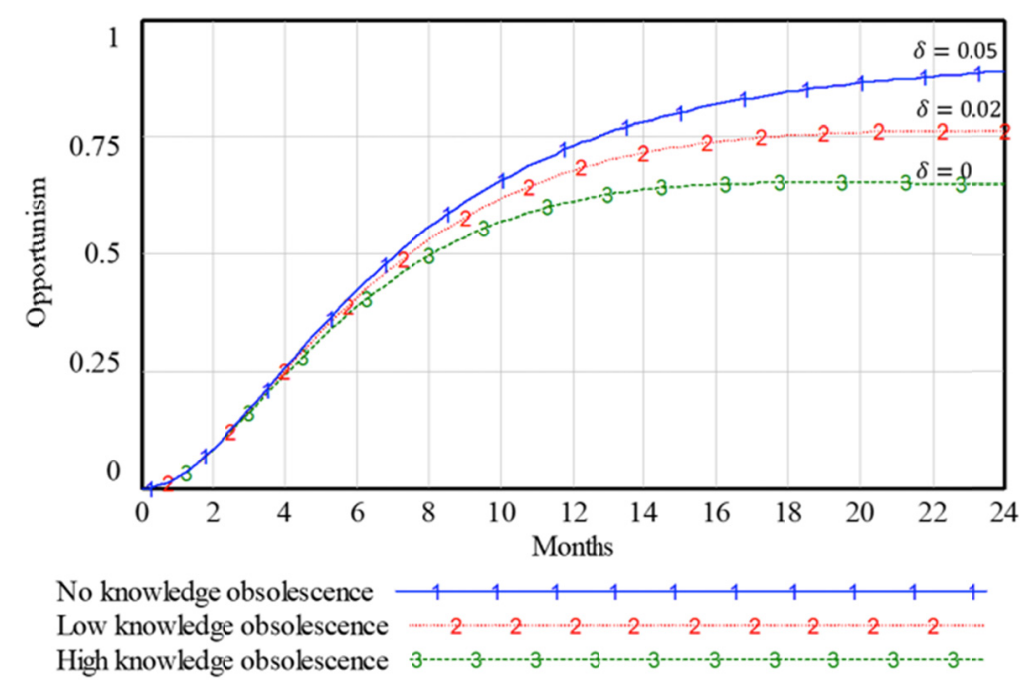

Figure 2 .

\subsection{Horizontal Knowledge Leakage in a Sharing Strategy: Experiment 2}

In experiment 2, we introduced in the formal model an additional element to show what happens when the knowledge symmetrically leaks among the suppliers in a network. In this case, knowledge not only leaks from the NE to suppliers, but knowledge spills over among the co-located suppliers as well. In other words, both vertical knowledge sharing and horizontal leakage facilitates a symmetrical knowledge diffusion in the cluster of suppliers.

Once shared, the knowledge does not assign any competitive advantage to any specific supplier since this knowledge is distributed symmetrically among all. As a consequence, the potential for suppliers' opportunistic behavior decreases.

To explore this scenario, equation 8 is amended as follows:

$$
\dot{K}=\frac{k^{g \cdot k^{d}}}{\tau^{k}}-K \cdot \delta
$$

In the equation (8.a) the parameter $\delta$ represents the speed at which the competitive potential of knowledge for suppliers' diversification outside the network decreases over time.

\section{Discussion}

Counterintuitively, simulations experiments suggest that increasing the speed at which knowledge symmetrically leaks in a network of suppliers may bring about an advantage for the NE.

For example, in figure 2, we compare two simulations respectively with $\delta=0$ and $\delta=0.05$.

The parameter $\delta$ represents the speed at which the knowledge loses its value due to symmetric distribution. Assuming that $\delta=0.05$ implies that the stock of knowledge loses $5 \%$ of its value every simulated month. In the vertical axis, we report the percentage growth in incentive for opportunism ( $O$ in equation 5$)$ among suppliers. As shown in the figure, the incentive for opportunistic behavior is lower with higher spillover. The reason is that if knowledge spillovers in a cluster of co-located firms, these firms are equally endowed with a resource that is not unique to any of them. What will be valuable for them is to continue to participate to the process of new knowledge creation. In this respect, the distributed knowledge looks like a co-specialized resources that quickly obsolesces when applied outside the cluster. 


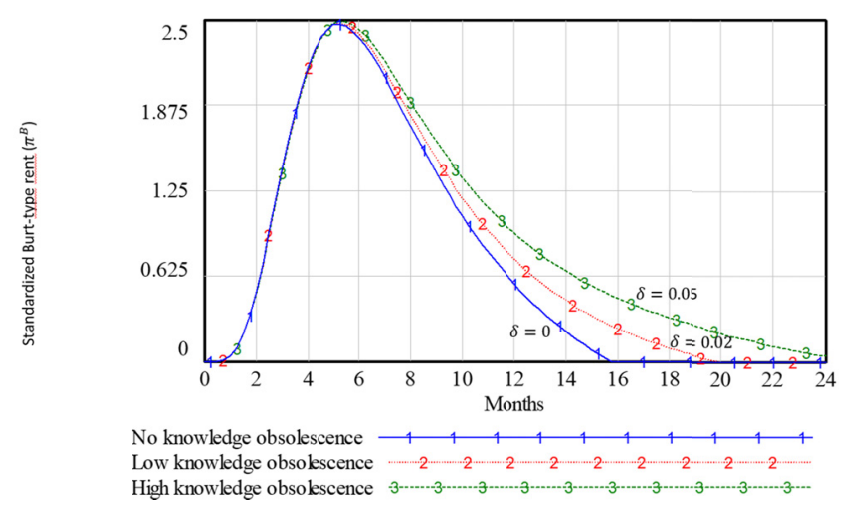

Figure 3.

For this reason, the substitution of Burt-type rents with Coleman-type rents is never fully complete since networked firms still partially depend on NE to nurture the process of knowledge creation. Burt-type peaks at the beginning of the simulation, when suppliers' population grows; as knowledge sharing and suppliers' empowerment increase, Burt-type rent erodes away and Coleman-type rent increases. Y'et, differently from the scenario reported in figure 1, in figure 3, Burt-type rents tend to resist longer despite the leakage of knowledge towards suppliers. In figure 3 , we simulated the model assigning to the parameter $\delta$ the values of 0 (no horizontal leakage), 0.02 (low horizontal leakage) and 0.05 (high horizontal leakage). On the vertical axis, we report the value of the Burt-type component of the rent (the Burt-type component labeled $\pi^{B}$ in equation 2).

Since the knowledge that they are sharing does not guarantee a sustainable competitive advantage but it needs to be continuously nurtured, networked firms have less incentive to free riding. Incentives of suppliers and NE are now partially converging. Because the shared knowledge does not guarantee a sustainable competitive advantage, the process of knowledge sharing mutates its nature; rather than a discrete exchange, the knowledge sharing process turns into a continuous process of accumulation that tights together firms' network and NE. What our experiments suggest is that it is not the knowledge per se that produces sustainable advantage but the process of creating and sharing knowledge.

The greater resilience of Burt-type component contributes to support the overall rents of the NE ( $\pi$ in equation 2). The horizontal distribution of knowledge within the network contributes to contain the loos of NE's bargaining power that may follow from the sharing of knowledge with suppliers. Thus, it becomes less cumbersome integrating advantages from brokerage and bargaining power (Burt-type component of rents) and knowledge sharing (Coleman-type component of rents). In figure 4, we show how the portion of knowledge that the focal NE is willing to share increases with $\delta$.

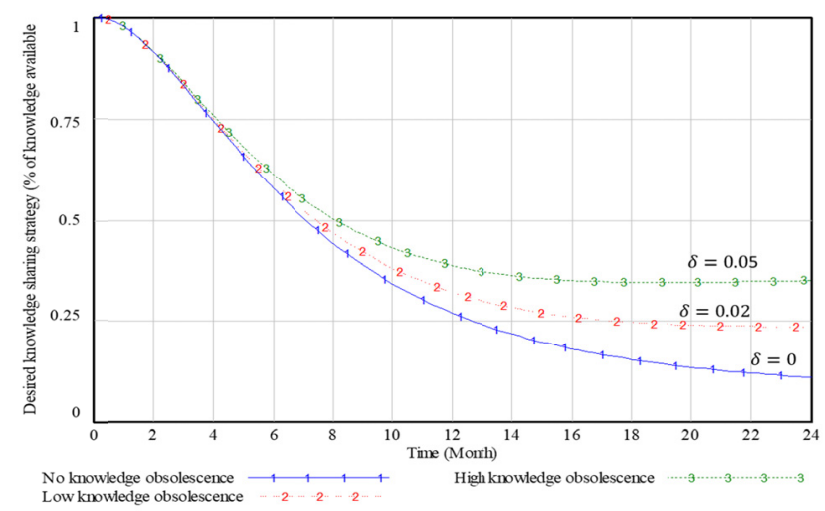

Figure 4.

In figure 5, we report a sensitivity analysis of the impact of $\delta$ on average sales. As shown, for realistic values of $\delta$ (in the range between $1 \%$ and $10 \%$ monthly obsolescence rate), to an increase of $\delta$ an increase of sales follows (beyond an obsolescence rate of $10 \%$ sales decrease given the fast erosion in the value of knowledge). 
This relationships is confirmed by figure 6 in which we plotted the 10 -year growth in average sales corresponding to different value of $\delta$. The faster the leakage, the higher the rents of the focal NE. Despite this simulated phenomenon seems counterintuitive, it brings about interesting insight and recasts the notion of co-specialization in a different perspective (Dyer \& Singh, 1996). Rather than asset co-specialization, what we observe here is the co-specialization into a knowledge creation process.

If knowledge erodes quickly, networked firms lose their value to act opportunistically and they will instead prefer to stick in the NE' network. In this case, networked firms can in fact extract individual rents from shared knowledge while the NE will maintain part of its Burt-type rents.

To clarify this concept, trust (Sako, 1992), rents from coordination (Dyer \& Singh, 1996; Dyer \& Noboeda, 2000; Kogut, 2000) and the pressures arising from the sunk costs of co-localized investments (Dyer \& Singh, 1996) are typical arguments to explain why firms remain clustered around exclusive relationships with one main NE. Rather, we provide conceptual tools to anticipate the emergence of co-specialization by investigating the nature of relevant knowledge and the dynamic of its exploitation. In this perspective, valuable and erodible knowledge is the incentive of the co-specialization that prevents NE from falling apart (figure 5).

Thus, we suggest that:

Proposition 1: The rate of knowledge obsolescence transforms a knowledge sharing process taking place between an NE and a firms' network into a continuous process of exchange that bind together the partners involved in the process.

Proposition 2: A high rate of knowledge obsolescence may be considered a form of co-sipecialization; however, rather that sunk costs, what keeps the networked firms together is the alignment of incemtives in producing and sharing new knowledge.

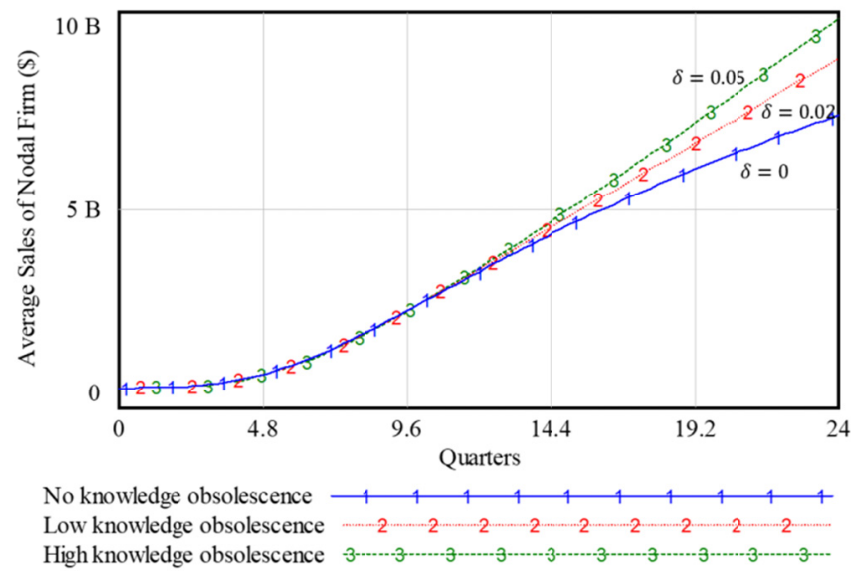

Figure 5 .

In addition, our work provides new lenses for the research that has previously emphasized the advantages of co-location. Advantages of firms' agglomerations are often associated with concepts like learning-by-doing and by-using, 'social networks' effects, user-producer relations, and various forms of Marshallian externalities which characterize evolutionary dynamics in the socio-economic domain, 'horizontal' and 'vertical' development of knowledge clusters (Maskell \& Malmberg, 2007), 'face-to-face' coordination and learning dynamics (Storper \& Venables, 2004), structural and collocation L advantages (Narula \& Santangelo, 2012). These effects have been illustrated in both the studies of Italian Districts (Brusco, 1982, 1999; Porter, 1998) and in the more current analyses of innovative startups rents co-located in Silicon Valley (Bottazzi et al., 2007; Engel, 2015). To this literature, we add the idea that co-location, by favoring the horizontal distribution of knowledge, increase the incentive of suppliers to remain linked to the knowledge production process that takes place at the level of the network. Therefore, we suggest that:

Proposition 3: The higher horizontal leakages of knowledge among suppliers, the rate of knowledge obsolescence, the lower the bargaining power of networked firms, the lower their ability to extract portions of Coleman-type rents from NEs.

In general, based on previous propositions, we can describe two different knowledge management strategies for NEs: 
Proposition 4.1: NEs adopt a "Brokerage" strategy when they exploit the lack of connection and information flows among suppliers thereby playing the role of brokers.

Adopting a Brokerage strategy, a NE exploits information asymmetries and plays the role of broker that selectively transfers knowledge without allowing for the creation of dense relationships within the network. In this case, the NE does not share its knowledge with all the other organizations and manages its network favoring dyadic relations with suppliers.

Proposition 4.2: NEs adopt a "Sharing" strategy when they facilitate the connections between all networked firms, creating networks characterized by redundant and multiple connections.

Sharing strategies generate networks that are dense of different kinds of connections: market exchanges, personal connections, collaborative and competitive relations, these latter facilitated by the same geographical location (cluster collocation). Moschera and Antonelli (2006), for example, underline the role of a well-known NE in the rail industry that foster R\&D consortia creations among its suppliers, which are localized in the Campania region (Italy), to obtain better economic advantages and increase their innovation's rate.

In our simulation study, we show that the two described strategies differently integrate portions of different types of rents. However, the association between the two knowledge management strategies and the types of rents is not intuitive or simple. Rather, portions of different types of rents are interlaced in the two knowledge management strategies.

In a dynamic perspective, for example, a brokerage strategy may be untenable so that Burt-type rents erode as knowledge is transferred to selected suppliers in the networks. This may happen because, the selected suppliers will have an advantage in respect to other suppliers and, therefore, their bargaining power will gradually increase. In this case, it would be then more advantageous for NEs to let the knowledge spread symmetrically in the network so to reduce the bargaining power of the originally selected suppliers. Interestingly, simulations teach us that asymmetry in knowledge distribution can be a double-edged sword. On the one hand, the asymmetry in knowledge distribution between NE and suppliers produces Burt-type rents. On the other hand, however, the asymmetry in knowledge distribution among the suppliers of network may create differentiated competitive positions so that specific suppliers increase their bargaining power vis-à-vis the NE.

In this respect, our work speaks to the issue of codificability of the knowledge to be transferred. As shown in figure 4, our simulation experiments suggest that the higher the obsolescence rate, the higher will be the share of knowledge that the NE is willing to share. In other words, the easily the knowledge leaks within the network, the higher is the incentive for the simulated NE to adopt a sharing strategy.

In this prospective, we expect that:

Proposition 5.1: The more tacit the knowledge to be shared, the harder the knowledge will horizontally leak and the lower the obsolescence rate will be. Therefore, the more convenient is for NEs to adopt a "Brokerage" strategy controlling the amount of knowledge shared so not to increase the bargaining power of selected suppliers.

Proposition 5.2: The more codified the knowledge to be shared, the easier the knowledge will spillover and the higher the obsolescence rate will be. Therefore, the more convenient is for NEs to adopt a "Sharing" strategy.

Following a similar line of reasoning, another thread of literature, focused on the cognitive distance between firms embedded in knowledge exchange. The research on cognitive distance suggests a direction to investigate how our knowledge management strategies cope with international contexts. Specifically, our framework supports the analysis of knowledge management in globally distributed networks.

For example, Foss (1999) has identified that relatively smaller 'cognitive distance' (i.e. the technical and linguistic differences between partners) enhances the process of knowledge transfer. Holtbrügge \& Berg (2004) showed that the source of knowledge (external and internal) and the characteristics of knowledge flows are affected by different firm-specific and country-specific variables, such as the cultural distance between the subsidiary and the NE while, according to Myers and Cheung (2008), it is influenced by market structure and organizational similarities and dissimilarities between buyers and suppliers.

Therefore, in transferring knowledge, we propose that NEs need to orchestrate the type of knowledge with the selection of a specific knowledge management strategy ("Brokerage" or "Sharing") depending on the expected cognitive distance between the organizations belonging to the same network:

Proposition 6.1: The higher the cognitive distance among network members, the harder the knowledge spillover and the lower the obsolescence rate will be. Therefore, the more convenient is for NEs to adopt a "Brokerage" 
strategy controlling the amount of knowledge shared so not to increase the bargaining power of selected suppliers.

Proposition 6.2: The lower the cognitive distance among network members, the easier the knowledge spillover and the higher the obsolescence rate will be. Therefore, the more convenient is for NEs to adopt a "Sharing" strategy.

Finally, our work, speaks as well to research on internationalization processes. For example, our findings supports NE's strategic decision process of de-localization. The short term cost advantage of a brokerage strategy based on the creation of a new suppliers' de-localized bridgeheads, need to be discounted with the likelihood of maintain bargaining power vis-à-vis selected foreign suppliers. On other hand, our paper suggests that NEs could invest in stable knowledge supplier's network by using a sharing strategy.

\section{Conclusions}

This paper addresses NEs' knowledge management strategies in networks.

Earlier studies have tended to be static; they have primarily used retrospective field studies focusing on the selection of the structure of supplier networks, rather than on the dynamics of their evolution. This paper uses formal modelling and computer simulation to tease out the dynamic strategic behaviors that an NE may employ in managing and coordinating a knowledge network. The paper highlights how the design of knowledge management strategies needs to consider the knowledge obsolescence rate since this latter produces consequences for NEs in terms of rents exploitation.

Our findings are particularly interesting as knowledge is becoming more and more distributed. This is true in almost every industry, non-imitable innovation are fewer as the technology, and the information are more global.

In this context, NEs may find it difficult to maintain Burt-type rents in the long term since the asymmetry in information allocation tends to be easily eliminated. on the other hand, suppliers will benefiting from sticking to the network and take the advantages of knowledge sharing. In this light, NEs may benefit from using a Brokerage knowledge management strategy in the short run. In the medium run, on the contrary, the simulation shows that NEs will benefit more from Coleman-type rents that entail a knowledge sharing strategy.

Concluding, the key contributions of the present work are as follows. The first contribution concerns the designing and the generation of empirically testable propositions on the different behaviors of two types of rents - Burt-type and Coleman-type. These rents are intertwined and hardly distinguishable in empirical studies. The authors believe that the effort to describe the model behavior for each of the two and to explore the connection between these behaviors and the unfolding patterns of evolution of both NE and supplier populations may illuminate fields to be empirically investigated.

Second, this study offers a conceptual framework that links the features of knowledge accumulation and the evolution of the suppliers' networks. While former studies focused on asset co-specialization and count on social norms to guarantee incentives alignment and control of free-riding behaviors, we propose an alternative, but complementary, point of view. More precisely, the contribution rests in the way we addressed the trade-off between sharing knowledge, for increasing the value of collaboration, or maintaining information asymmetry to extract rents from such asymmetry. We believe that the conundrum is produced by the conceptualization of knowledge-based resources as stocks for which value generation is directly associated to the availability of the resource and the deployment of relative property rights. The present study takes a different stance, by taking a dynamic point of view, we focus on the flows that characterize the time-dependent value of knowledge-based resources. In this respect, we suggest that what creates value are the dynamic properties of the process of knowledge accumulation and sharing rather than specific pieces of information shared (Dierickx \& Cool, 1989). Therefore, what keeps NE's suppliers network tight together is the fact that the value of knowledge shared may rapidly erodes. Suppliers' bargaining power, and their incentives to abandon the network, is reduced by the fact that the knowledge shared becomes obsolete and what assures long-term performances is rather to participate in the process of knowledge creation and sharing.

Of course, the use of an approach grounded in formal modelling and simulation has its limits. One of the limits is that the need to narrowly defining the boundaries of the addressed theoretical problem might lead to over simplifications.

For example, in the present study the suppliers' network is modelled as a single decision-maker thereby overlooking the complex relationships that may emerge among firms in the population of suppliers. Obviously, this is a strong assumption. Along the lines that were illuminated, further research ought to explore how, while the network of suppliers evolves, small suppliers develop new positions and new forms of exchange practices 
that include the capability to coordinate, integrate and configure exchange activities with buyers as well as with other subcontractors.

In a similar vein, usually suppliers' appropriation of rents results in the enlargement of the suppliers' population. The idea, again, was to consider the population as one actor; thus, the increase of the population follows from the increase in the total resources available for the providers to survive. In other words, we modelled it in such a way that the appropriation of rents leads to an increase in the carrying capacity of the network that, in turn, allows a higher number of suppliers to survive. A future avenue to develop this work includes the modelling of the pattern of distribution of bargaining power within the suppliers' network in order to explore the emerging non-homogenous appropriation of rents within the NE's network itself.

\section{References}

Arshinder, K., Kanda, A., \& Deshmukh, S. G. (2011). A Review on Supply Chain Coordination: Coordination Mechanisms, Managing Uncertainty and Research Direction. In T. M. Choi, \& T. E. Cheng (Eds.), Supply Chain Coordination under Uncertainty, International Handbooks on Information Systems. Springer-Verlag Berlin-Heidelberg.

Bottazzi, G., Dosi, G., Fagiolo, G., \& Secchi, A. (2007). Modeling Industrial Evolution in Geographical Space. Journal of Economic Geography, 7(5), 651-672. https://doi.org/10.1093/jeg/lbm024

Brusco, S. (1982). The Emilian Model: Productive Decentralisation and Social Integration. Cambridge Journal of Economics, 6(2), 167-184. https://doi.org/10.1093/oxfordjournals.cje.a035506

Brusco, S. (1999). The rules of the game in industrial districts. In A. Grandori (Ed.), Interfirm networks: organization and industrial competitiveness (pp. 17-40). Routledge, London.

Burt, R. S. (1992). The Structural Holes: The Social Structure of Competition. Cambridge, MA: Harvard University Press.

Burt, R. S. (2000). The Network Structure of Social Capital. Research in Organizational Behavior, 22, 345-423. http://dx.doi.org/10.1016/S0191-3085(00)22009-1

Coff, R. W. (1999). When Competitive Advantage Doesn't Lead to Performance: The Resource-based View and Stakeholder Bargaining Power. Organization Science, 10(2), 119-132. https://doi.org/10.1287/orsc.10.2.119

Cohen, W. M., \& Levinthal, D. A. (1990). Absorptive Capacity: A New Perspective on Learning and Innovation. Administrative Science Quarterly, 35(1), 128-152. http://psycnet.apa.org/doi/10.2307/2393553

Coleman, J. (1990). Foundations of Social Theory. Cambridge, MA: Harvard University Press.

Cua, K., McKone, K., \& Schroeder, R. G. (2001). Relationships between Implementation of TQM, JIT, and TPM and Manufacturing Performance. Journal of Operations Management, 19(6), 675-694. https://doi.org/10.1016/S0272-6963(01)00066-3

Dierickx, I., \& Cool, K. (1989). Asset Stock Accumulation and Sustainability of Competitive Advantage, Management Science, 35(12), 1504-1511. https://doi.org/10.1287/mnsc.35.12.1504

Dore, R. (1983). Goodwill and the Spirit of Market Capitalism. British Journal of Sociology, 34, 459-482. http://psycnet.apa.org/doi/10.2307/590932

Duanmu J. L., \& Fai, F. M. (2007). A Processual Analysis of Knowledge Transfer: From Foreign NEs to Chinese Suppliers. International Business Review, 16, 449-473.

Dwyer, F. R., \& Walker, O. C. (1981). Bargaining in an Asymmetrical Power Structure. Journal of Marketing, 45(1), 104-115. http://psycnet.apa.org/doi/10.2307/1251724

Dyer J. H., \& Singh, H. (1996). The relational view: cooperative strategy and sources of inter-organizational competitive advantage. Academy of Management Review. 23(4), 660-679. http://psycnet.apa.org/doi/10.2307/259056

Dyer, J. H., \& Nobeoka, K. (2000). Creating and Managing a High-Performance Knowledge-Sharing Network: The Toyota Case. Strategic Management Journal, 21(3), 345-367. https://doi.org/10.1002/(SICI)1097-0266(200003)21:3\%3C345::AID-SMJ96\%3E3.0.CO;2-N

Easterby-Smith, M., Thorpe, R., \& Jackson, P. R. (2008). Management Research (3rd ed.). Thousand Oaks: Sage.

Foss, N. (1999). The Use of Knowledge in Firms. Journal of Institutional and Theoretical Economics (JITE) / Zeitschrift Für Die Gesamte Staatswissenschaft, 155(3), 458-486. Retrieved from http://www.jstor.org/stable/40752149

Foss, N. J., Husted, K., \& Michailova, S. (2010). Governing Knowledge Sharing in Organizations: Levels of Analysis, Governance Mechanisms and Research Directions. Journal of Management Studies, 47(3), 455-482. https://doi.org/10.1111/j.1467-6486.2009.00870.x

Frishammar, J. Ericsson, K., \& Pate, P. C. (2015). The Dark Side of Knowledge Transfer: Exploring Knowledge 
Leakage in Joint R\&D Projects. Technovation, 41(42), http://dx.doi.org/10.1016/j.technovation.2015.01.001

Frohlich, M. T., \& Westbrook, R. (2001). Arcs of Integration: An International Study of Supply-Chain Strategies. Journal of Operations Management, 19(2), 185-200. http://dx.doi.org/10.1016/S0272-6963(00)00055-3

Frohlich, M. T. (2002). E-Integration in the Supply Chain: Barriers and Performance. Decision Sciences, 33(4), 537-547. https://doi.org/10.1111/j.1540-5915.2002.tb01655.x

Frooman, J. (1999). Stakeholder Influence Strategies. Academy of Management Review, 24(2), 191-205. http://psycnet.apa.org/doi/10.2307/259074

Gary, M. S. (2005). Implementation Strategy and Performance Outcome in Related Diversification. Strategic Management Journal, 26(7), 643-664. https://doi.org/10.1002/smj.468

Gray, B. (1989). Collaborating: Finding Common Ground for Multiparty Problems. San Francisco, CA: Jossey-Bass.

Greenwood, R., \& Suddaby, R. (2006). Institutional Entrepreneurship in Mature Fields: The Big Five Accounting Firms. Academy of Management Journal, 49(1), 27-48. https://doi.org/10.5465/amj.2006.20785498

Heide, J. B. (1994). Interorganizational Governance in Marketing Channels. Journal of Marketing, 58(1), 71-85. http://psycnet.apa.org/doi/10.2307/1252252

Holtbrügge, D., \& Berg, N. (2004). Knowledge Transfer in Multinational Corporations, Evidence from Germany Firms. Management International Review, 44, 129-146. https://doi.org/10.1007/978-3-322-91001-1_7

Huizingh, K. R. E. (2011). Open Innovation: State of The Art and Future Perspectives. Technovation, 31, 2-9. https://doi.org/10.1016/j.technovation.2010.10.002

Kogut, B. (2000). The Network as Knowledge: Generative Rules and The Emergence of Structure. Strategic Management Journal. Special Issue: Strategic Networks, 21(3), 405-425. https://doi.org/10.1002/(SICI)1097-0266(200003)21:3\%3C405::AID-SMJ103\%3E3.0.CO;2-5

Kulp, S. C., Lee H. L., \& Ofek, E. (2004). Manufacturer Benefits from Information Integration with Retail Customers. Management Science, 50(4), 431-444. https://doi.org/10.1287/mnsc.1030.0182

Lant, T. K. (1992). Aspiration Level Adaptation: An Empirical Exploration. Management Science, 38(5), 623-644. https://doi.org/10.1287/mnsc.38.5.623

Lant, T. K., \& Mezias, S. J. (1992). An Organizational Learning Model of Convergence and Reorientation. Organization Science, 3(1), 47-71. https://doi.org/10.1287/orsc.3.1.47

Magretta, J. (1998). The Power of Virtual Integration: An Interview with Dell Computer's Michael Dell. Harvard Business Review, 76(2), 72-85.

Malerba, F., Nelson, R., Orsenigo, L., \& Winter, S. (1999) History-Friendly' Models of Industry Evolution: The Computer Industry. Industrial and Corporate Change, 8(1), 3-40. https://doi.org/10.1093/icc/8.1.3

Maskell, P., \& Malmberg, A. (2007). Myopia, Knowledge Development and Cluster Evolution. Journal of Economic Geography, 7, 603-618. https://doi.org/10.1093/jeg/lbm020

Milgrom, P., \& Roberts, J. (1992). Economics, Organizations and Management. Englewood Cliffs, NJ: Prentice-Hall.

Mollona, E. (2017). How Visible is the Visible Hand of Top Management in Strategic Renewals? Guided Evolution and the Intraorganizational Ecology Model of Adaptation. Industrial and Corporate Change, 26(4), 689-708. https://doi.org/10.1093/icc/dtw049

Moschera, L., \& Antonelli, G. (2006). Regolazione istituzionale e strategie dei singoli attori per la competitività di un cluster. In R. Mercurio (edt): Organizzazione, regolazione e competitività (pp. 183-198). The McGraw-Hill Companies, Milano

Mudambi, S., \& Tallman, S. (2010). Make, Buy or Ally? Theoretical Perspectives on Knowledge Process Outsourcing through Alliances. Journal of Management Studies, 47(8), 1434-1456. https://doi.org/10.1111/j.1467-6486.2010.00944.x

Myers, M. B., \& Cheung, M. (2008). Sharing Global Supply Chain Knowledge, MIT Sloan Management Review, 49, 67-73.

Narula, R., \& Santangelo, G. D. (2012). Location and Collocation Advantages in International Innovation. Multinational Business Review, 20 (1), 6-5. https://doi.org/10.1108/15253831211217161

Pfeffer, J. (1982). Organizations and Organization Theory. Marshfield, MA: Pitman Publishing.

Romo, F. P., \& Schwartz M., (1995), Structural Embeddedness of Business Decisions: A Socio-Logical Assessment of the Migration Behavior of Plants in New York State between 1960 and 1985. American Sociological Review, 60, 874-907.

Rota, K., Thierry, C., \& Bell, G. (2002). Supply Chain Management: A Suppliers Perspective. Production, Planning and Control, 13(4), 370-380. https://doi.org/10.1080/09537280210130469 
Sahin, F., \& Robinson Jr., E. P. (2005). Information Sharing and Coordination in Make-To-Order Supply Chains. Journal of Operations Management, 23(6), 579-598. https://doi.org/10.1016/j.jom.2004.08.007

Sako, M. (1999). Quality and Trust. Inter-firm Relations in Britain \& Japan. Cambridge, UK: Cambridge University Press.

Sastry, M. A. (1997). Problems and paradoxes in a model of punctuated organizational change. Administrative Science Quarterly, 42(2), 237-275. https://doi.org/10.2307/2393920

Skjoett-Larsen, T. (2000). European Logistics Beyond 2000, International Journal of Physical Distribution \& Logistics Management, 30(5), 377-387. https://doi.org/10.1108/09600030010336144

Staber, U. (1998). Inter-Firm Co-Operation and Competition in Industrial Districts. Organization Studies, 19(4), 4701-4724. https://doi.org/10.1177/017084069801900407

Sterman, J. D. (1987). Expectations Formation in Behavioral Simulation Models. Behavioral Science, 32(3), 190-211.

Storper, M., \& Venables, A. (2004). Buzz: Face-To-Face Contact and The Urban Economy. Journal of Economic Geography, 4, 351-370. https://doi.org/10.1093/jnlecg/lbh027

Tortoriello, M., McEvily, B., \& Krackhardt D. (2015). Being a Catalyst of Innovation: The Role of Knowledge Diversity and Network Closure. Organization Science, 26(2), 423-438. https://doi.org/10.1287/orsc.2014.0942

Uzzi B. (1997). Social Structure and Competition in Interfirm Networks: The Paradox of Embeddedness. Administrative Science Quarterly, 42(1), 35-67. http://psycnet.apa.org/doi/10.2307/2393808

Watson, N., \& Zheng, Y. S. (2005). Decentralized Serial Supply Chains Subject to Order Delays and Information Distortion: Exploiting Real-Time Sales Data. Manufacturing \& Service Operations Management, 7(2), 152-168. https://doi.org/10.1287/msom.1050.0074

Yan, A., \& Gray B. (2001). Antecedents and Effects of Parent Control in International Joint Ventures. Journal of Management Studies, 38(3). 393-394. https://doi.org/10.1111/1467-6486.00242

\section{Notes}

Note 1. The joint venture literature identifies two sources of bargaining power: context-based and resource-based (Yan \& Gray, 2001; Coff, 1999). Context-based sources of bargaining power derive from the possibility that a participant maintains to walk away from a transaction, such as when the participant has other alternatives or when the deal is not as strategically important to the participant. Resource-based sources of bargaining power derive from the critical resources that a participant brings to the table, such as money, expertise and technology. Along similar lines, resource dependency theory (Frooman, 1999; Pfeffer, 1982) provides a compelling argument that organizations must 'attend to the demands of those in its environment that provide it resources important and necessary for its continued survival' (Pfeffer, 1982, p. 193).

Note 2. The value of the generic state variable $(\mathrm{X})$, at time $(t)$, is the integral of previous changes as follows: $X_{t+\Delta t}=X_{0}+\int_{t}^{t+\Delta t} \dot{X}$

where $X \dot{=} \frac{d X}{d t}$. In the model, the four state variables: $S, D, T$ and $P$ are calculated by integrating their rates of change.

Note 3. This formulation has been previously used to describe processes of 'psychological smoothing' (Forrester, 1961), in which decision-making is anchored to past historical data and incrementally adapts to incoming information (Sterman, 1987; Lant, 1992; Schneider, 1992; Sastry, 1997).

Note 4. Underpinning the formulation of the number of firms that may survive in the local cluster is the hypothesis that firms in the network have similar characteristics and hence they share equally the market. In addition, we assumed that the firms are perfectly mixed in the stock $P_{t}$ (Sterman, 2000: 416) and, thus, the order of entry in the stock is irrelevant to the order of exit.

\section{Copyrights}

Copyright for this article is retained by the author(s), with first publication rights granted to the journal.

This is an open-access article distributed under the terms and conditions of the Creative Commons Attribution license (http://creativecommons.org/licenses/by/4.0/). 